\title{
60S dynamic state of bacterial ribosome is fixed by yeast mitochondrial initiation factor 3
}

Sergey Levitskii ${ }^{1}$ ， Ksenia Derbikova ${ }^{1}$ ， Maria V Baleva ${ }^{1}$ ， Anton Kuzmenko ${ }^{1}$ ， Andrey V Golovin ${ }^{2,3,4}$, Ivan Chicherin ${ }^{1}$, Igor A Krasheninnikov ${ }^{1}$, Piotr Kamenski ${ }^{\text {Corresp. } 1}$

1 Faculty of Biology, Moscow State University, Moscow, Russia

2 Faculty of Bioengineering and Bioinformatics, Moscow State University, Moscow, Russia

3 Institute of Molecular Medicine, Sechenov First Moscow State Medical University, Moscow, Russia

4 Faculty of Computer Science, Higher School of Economics, Moscow, Russia

Corresponding Author: Piotr Kamenski

Email address: peter@protein.bio.msu.ru

The processes of association and dissociation of ribosomal subunits are of great importance for the protein biosynthesis. The mechanistic details of these processes, however, are not well known. In bacteria, upon translation termination, ribosome dissociates into subunits which is necessary for its further involvement into new initiation step. The dissociated state of ribosome is maintained by initiation factor 3 (IF3) which binds to free small subunits and prevents their premature association with the large subunits. In this work, we have exchanged IF3 in E.coli cells by its ortholog from Saccharomyces cerevisiae mitochondria (Aim23p) and showed that yeast protein cannot functionally substitute the bacterial one and is even slightly toxic for bacterial cells. Our in vitro experiments have demonstrated that Aim23p does not split E.coli ribosomes into subunits. Instead, it fixes a state of ribosomes characterized by sedimentation coefficient about 605 which is not a stable structure but rather reflects a shift of dynamic equilibrium between associated and dissociated states of the ribosome. Mitochondria-specific terminal extensions of Aim23p are necessary for "60S state" formation, and molecular modeling results point out that these extensions might stabilize the position of the protein on the bacterial ribosome. 
$1 \quad 60 \mathrm{~S}$ dynamic state of bacterial ribosome is fixed by yeast mitochondrial 2 initiation factor 3

3

4 Sergey Levitskii ${ }^{1}$, Ksenia Derbikova ${ }^{1}$, Maria V. Baleva ${ }^{1}$, Anton Kuzmenko ${ }^{1}$, Andrey V.

5 Golovin $^{2,3,4}$, Ivan Chicherin ${ }^{1}$, Igor A. Krasheninnikov ${ }^{1}$, Piotr Kamenski ${ }^{*}$

${ }^{1}$ Faculty of Biology, M.V.Lomonosov Moscow State University, 1/12 Leninskie Gory, 8 Moscow 119234, Russia

${ }^{2}$ Faculty of Bioengineering and Bioinformatics, M.V.Lomonosov Moscow State 10 University, 1/73 Leninskie Gory, Moscow 119234, Russia

${ }^{3}$ Sechenov First Moscow State Medical University, Institute of Molecular Medicine, 8-2

12 Trubetskaya str., Moscow 119991, Russia

${ }^{4}$ Higher School of Economics, Faculty of Computer Science, 3 Kochnovsky pr., Moscow 14 125319, Russia.

15

16

17

Present address:

Anton Kuzmenko, Institute of Molecular Genetics, Russian Academy of Science, Moscow 123182, Russia.

*Corresponding author: Piotr Kamenski. E-mail: peter@protein.bio.msu.ru 


\section{ABSTRACT}

The processes of association and dissociation of ribosomal subunits are of great importance for the protein biosynthesis. The mechanistic details of these processes, however, are not well known. In bacteria, upon translation termination, ribosome dissociates into subunits which is necessary for its further involvement into new initiation step. The dissociated state of ribosome is maintained by initiation factor 3 (IF3) which binds to free small subunits and prevents their premature association with the large subunits. In this work, we have exchanged IF3 in E.coli cells by its ortholog from Saccharomyces cerevisiae mitochondria (Aim23p) and showed that yeast protein cannot functionally substitute the bacterial one and is even slightly toxic for bacterial cells. Our in vitro experiments have demonstrated that Aim $23 p$ does not split E.coli ribosomes into subunits. Instead, it fixes a state of ribosomes characterized by sedimentation coefficient about $60 \mathrm{~S}$ which is not a stable structure but rather reflects a shift of dynamic equilibrium between associated and dissociated states of the ribosome. Mitochondriaspecific terminal extensions of Aim23p are necessary for "60S state" formation, and molecular modeling results point out that these extensions might stabilize the position of the protein on the bacterial ribosome.

\section{INTRODUCTION}

Upon termination of protein biosynthesis in bacteria, 70S ribosome dissociates into small (30S) and large (50S) subunits. Free small subunit then takes part in de novo formation of the initiation complex with mRNA, initiator tRNA, and several initiation factors. Binding of the large subunit promotes release of the initiation factors, and assembled $70 \mathrm{~S}$ ribosomes begins a new round of translation (for review, see (Laursen et al. 2005)).

It is known that two proteins, namely RRF and EF-G, are responsible for bacterial ribosomes dissociation into subunits after termination of protein biosynthesis (Zavialov et al. 2005) (Peske et al. 2005). Once free 30S and 50S subunits appear, initiation factor 3 (IF3) binds the small subunit in order to keep it apart from the large one (Zavialov et al. 2005). This stage is, in fact, the very first stage of the translation initiation process; $30 \mathrm{~S} \bullet \mathrm{IF} 3$ complex becomes the basis for the full-size initiatory complex formation which includes Shine-Dalgarno sequence of mRNA, initiator tRNA, and initiation factors 1 and 2. It is worth mentioning that anti-association 
54 activity of IF3 is definitely of passive mode: it does not promote dissociation of the ribosome 55 into subunits but instead binds to free small subunit and prevents its re-association with the large one (Gualerzi et al. 1977) (Gottleib et al. 1975).

The exact mechanism of ribosome dissociation into subunits remains unclear. This is due to methodological complications of studying this fast and dynamic process. In kinetic study, a model was proposed that assumed the existence of several consecutive conformations of ribosome in course of its dissociation; IF3 was hypothesized to be a potential effector of corresponding conformational changes which could shift the equilibria between different states of dissociating ribosome (Goss et al. 1980). It can be assumed that these conformations might be characterized by different sedimentation coefficients, less than $70 \mathrm{~S}$ but probably more than $50 \mathrm{~S}$. Indeed, a ribosomal $\sim 60 \mathrm{~S}$ state was described in in vitro experiments; this state was formed under specific experimental conditions (Morimoto 1969). The authors used a term "60S component" and postulated that this was a new stable intermediate of the subunits dissociation / association reaction and that this intermediate was just "swollen 70S" (Morimoto 1969). Further investigations, however, have demonstrated that the exact sedimentation coefficient of this "swollen 70S" depends on the sedimentation speed and on the initial 70S concentration (Spirin 1971). These results fit very well to the above-discussed hypothesis about consecutive conformational changes of $70 \mathrm{~S}$ ribosome during dissociation. However, none of these intermediate states has been seen as stable structure.

In this work, we investigated the effects of yeast mitochondrial IF3, Aim23p, on the E.coli translation. The idea comes from the recent work of Ayyub and colleagues where it has been demonstrated that mammalian mitochondrial IF3 (mtIF3), although being unable to fully substitute for IF3 in E.coli, exhibits some functional activity in bacterial cells (Ayyub et al. 2018). We exchanged infC gene (coding for IF3) in bacteria by AIM23 gene and found that Aim23p cannot substitute the cognate factor. Moreover, Aim23p was slightly toxic for the bacterial cell which was mediated by mitochondria-specific parts of the protein, namely its Nand $\mathrm{C}$-terminal extensions. Our in vitro investigations have revealed that Aim23p does bind to E.coli ribosome and fixes its unusual state with sedimentation coefficient about $60 \mathrm{~S}$. This state can be further transformed into fully dissociated state if Am23p concentration is increased. According to the results of wet experiments and molecular modeling, terminal extensions of Aim23p might be responsible for 60S state fixation. 
85

86

87

88

89

90

91

92

93

94

95

96

97

98

99

100

101

102

103

104

105

106

107

108

109

110

111

112

113

114

\section{MATERIALS AND METHODS}

Plasmids, E.coli strains and oligonucleotides used in the work may be found in Tables 1,2 , and 3 , respectively.

\section{Cloning and standard procedures}

Different versions of AIM23 (S.cerevisiae) and infC (E.coli) genes were cloned into above-mentioned vectors by standard PCR-restriction-ligation approach.

Western-blot was performed by standard protocol using the rabbit antibodies against 6His-tagged recombinant Aim23p (produced on our order by Almabion).

\section{Construction of mutant E.coli strains (Thomason et al. 2007)}

Genomic disruption of infC gene coding for IF3 was carried out in the E.coli strain MG1655. Cassette for infC genomic disruption containing the chloramphenicol resistance gene was prepared by PCR from pKD3 plasmid. Primers contained 5'-parts designed for the homologous recombination into the target genome site. The cassette was then delivered into E.coli cells by electroporation. These cells initially contained pKD46 plasmid encoding for recombinase, as well as pACDH plasmid containing infC gene. Clones where recombination took place were selected on chloramphenicol-containing medium and screened by PCR.

For transferring the bacterial genetic material to phage $\mathrm{P} 1,5 \mathrm{ml}$ of E.coli culture in logarhythmic growth phase was infected by 100 ul of phage suspension. The mixture was incubated at $37^{\circ} \mathrm{C}$ for 3 hours with shaking and centrifuged at $9200 \mathrm{~g}$ for 10 minutes. The phagecontaining upper fraction was taken and filtered through 0.45 um filter.

For generation of the experimental E.coli strains, the MG1655 cells containing pBAD plasmid with cloned infC gene were transformed by the plasmids coding for IF3 or different variants of Aim23p. $2 \mathrm{ml}$ of $\mathrm{ON}$ cultures were pelleted and resuspended in $1 \mathrm{ml}$ of $10 \mathrm{mM} \mathrm{CaCl}_{2}$, $5 \mathrm{mM} \mathrm{MgSO}_{4}$. Suspensions were 100 ul aliquoted, then half a volume of P1 lysate was added, and the mixtures were incubated at $37^{\circ} \mathrm{C}$ for 30 minutes without shaking. Then $1 \mathrm{ml}$ of LB medium and $200 \mathrm{ul}$ of sodium citrate were added followed by the incubation at $37^{\circ} \mathrm{C}$ for 1 hour 
115 with shaking. The cells were plated on the agar dishes with antibiotics, $0,02 \%$ arabinose and

$1165 \mathrm{mM}$ sodium citrate. Screening of the clones was performed by PCR.

117 The growth curves of E.coli strains were registered in automatic mode using microplate

118 reader Infinite M200 PRO (Tecan Instruments).

119

120

\section{Ribosome purification and analysis}

121

Ribosomes were isolated from E.coli strain MG1655 according to (Rivera et al. 2015) with minor changes. Briefly, bacterial cells from $1 \mathrm{~L}$ culture with $\mathrm{OD}_{600} \sim 0.6$ were collected, lysed, ribosomes from clarified lysate were sedimentated through 10\% sucrose cushion, and dissolved in minimal volume of $10 \mathrm{mM}$ Tris- $\mathrm{HCl} \mathrm{pH} \mathrm{7,0;} 60 \mathrm{mM} \mathrm{KCl,} 60 \mathrm{mM} \mathrm{NH}_{4} \mathrm{Cl}, 7 \mathrm{mM}$ magnesium acetate, $7 \mathrm{mM} \beta$-mercaptoethanol, $0.25 \mathrm{mM}$ EDTA. Isolated ribosomes were stored at $-80^{\circ} \mathrm{C}$. For dissociation reaction, approximately 24 pmoles (one unit of $\mathrm{OD}_{260}$ ) of ribosomes were mixed with different amounts of recombinant Aim23p, IF3, or Aim23 $\Delta \mathrm{N} \Delta \mathrm{C}$ in the aboveindicated buffer. Mixtures were incubated at $37^{\circ} \mathrm{C}$ for $30 \mathrm{~min}$, and then applied on $15 \%-40 \%$ continuous sucrose gradients prepared on the same buffer. Samples were centrifuged for 18 hours at $100,000 \mathrm{~g}$, and then fractionated from top to bottom (45 fractions each of $250 \mathrm{ul}$ were taken). Absorbencies of all fractions at $260 \mathrm{~nm}$ were measured.

In case of cross-linking, between the incubation with proteins and loading on the sucrose gradient, formaldehyde was added to ribosome preparations up to $1 \%$, and the mixtures were incubated for 30 minutes on ice.

\section{Molecular modeling}

Homology model of Aim23p complex with E.coli 30S subunit was done with Modeller 9.17 (Sali \& Blundell 1993) (script may be found in Supplementary Information). For building of this model, we have used known structure of bacterial 30S subunit complex with the cognate IF3

140 (Pioletti et al. 2001), as well as sequence alignment of Aim23p with E.coli IF3 and other orthologs (Atkinson et al. 2012).

Folding of Aim23p N-terminal extension was done with AbinitioFold protocol (Bonneau et al. 2002) (Bonneau et al. 2001) on base of fragments obtained from Robetta web server (Kim et al. 2004). Simulation was stopped after 180000 decoys were collected. Homology modeling with new conformation of N-terminal extension was done with Modeller 9.17 (Sali \& Blundell 
146 1993). Conformation of the C-terminal extension was equilibrated with FloppyTail protocol from

147 Rosetta (Kleiger et al. 2009). Spatial structure visualization was done with the PyMOL

148 Molecular Graphics System, Version 2.0 (Schrödinger, LLC).

149

150

RESULTS

151

152

153

Full-length Aim23p is undesirable for E.coli cells due to its terminal extensions.

154

As it has been already mentioned in Introduction, mammalian mtIF3 possesses some functional activity in E.coli cells (Ayyub et al. 2018). On the other hand, we have previously demonstrated that E.coli IF3 may partially rescue the growth defects of the yeast strain lacking Aim23p (Kuzmenko et al. 2014). Moreover, Aim23p was shown to bind the small subunit of bacterial ribosome in vitro (Atkinson et al. 2012). Taken together, these findings have allowed us to hypothesize that Aim23p might be at least partially functional in E.coli cells as initiation factor 3 .

To verify this hypothesis, we have constructed three plasmids for further delivery into E.coli cells, coding for either cognate IF3 (positive control), Aim23p, or Aim23p without its mitochondria-specific N- and C-terminal extensions (Aim $23 \Delta \mathrm{N} \Delta \mathrm{C})$. This last construct was designed in order to specifically check possible effects of Aim23p terminal extensions on bacterial translation: theoretically, these protein parts, being mitochondria-specific, might not be needed for protein biosynthesis in E.coli. Cloned genes of Aim23p and Aim $23 \Delta \mathrm{N} \Delta \mathrm{C}$ did not contain sequences coding for mitochondrial targeting signal. Thereafter, we have disrupted E.coli infC gene coding for IF3. This gene contains the promoter for the expression of the downstream gene (Wertheimer et al. 1988), so we have removed only first 153 nucleotides of infC gene from the bacterial genome. Since IF3 is indispensable for bacteria, before disruption we have transformed E.coli with the plasmid bearing infC gene under control of glucose-repressible promoter. Finally, we have delivered the above-described plasmids into bacterial cells and disrupted the genomic copy of infC gene. The scheme of bacterial strains engineering is presented on Fig. 1A.

Then, we down-regulated the expression of infC gene in these strains with glucose and measured their growth rates. The resulting curves may be found in Fig. 1B. The strain bearing wild-type infC gene on the plasmid grows normally, with fast entering the logarithmic phase and 
177 reaching the plateau. The strain carrying empty vector shows no growth at first 10 hours of

178 incubation which is easily explained by the absence of infC gene. However, slow growth has

179 been detected afterwards, probably as a result of glucose-repressed promoter leakage which, in

180 turn, allows minimal amount of IF3 to be synthesized. If E.coli cells contain Aim $23 \Delta \mathrm{N} \Delta \mathrm{C}$, the

181 corresponding strain's growth curve is almost identical to that of the strain containing an empty

182 vector. This clearly indicated the impossibility of Aim $23 \Delta \mathrm{N} \Delta \mathrm{C}$ to functionally substitute IF3 in

183 bacterial cells. The most interesting case is definitely the bacterial strain bearing the full-size

184 Aim23p. This strain, although reaching finally the level of the strain containing an empty vector, 185 grows measurably slower than strain containing an empty vector. This means that the full-size

186 Aim23p, but not Aim $23 \Delta \mathrm{N} \Delta \mathrm{C}$, negatively affects the viability of E.coli cells. It is rather possible

187 that the terminal extensions of Aim23p may somehow interrupt the bacterial translation.

188

Terminal extensions provide the ability of Aim23p to fix an unusual state of E.coli

ribosomes.

191 The above-described unusual effect of Aim23p in E.coli cells has led us to study the

192 interaction of Aim23p with E.coli ribosomes in vitro. It is well known that adding cognate IF3 to

193 purified bacterial ribosomes shifts the equilibrium of the ribosome dissociation reaction making

194 the dissociated state preferable (Gottleib et al. 1975). Based on this, we have purified ribosomes

195 from E.coli cells, incubated them with the recombinant IF3 (positive control), or Aim23p, or

196 Aim $23 \Delta \mathrm{N} \Delta \mathrm{C}$, fractionated the reactions by sucrose gradient centrifugation and analyzed the

197 corresponding sedimentation profiles by measuring the optical densities of the fractions at 260

$198 \mathrm{~nm}$. The results of our experiment are presented in Fig. 2A. First of all, sedimentation profile of

199 the ribosome sample with no proteins added was characterized by clear UV peaks of 30S and

200 50S subunits, as well as the whole $70 \mathrm{~S}$ ribosomes, with the latter being most pronounced.

201 Adding IF3, as expected, led to the complete dissociation of ribosomes into subunits

202 (disappearance of the 70S peak and significant increase of the 30S and 50S peaks) while adding

203 of Aim $23 \Delta \mathrm{N} \Delta \mathrm{C}$ gave no effect on the sedimentation profile. This was also expected: in our in

204 vivo experiments, this protein could not substitute for the cognate IF3 in E.coli cells (see Fig.1).

205 The profile of sedimentation has been curiously changed with adding the full-size Aim23p. This

206 protein caused a fusion of 50S and 70S peaks with the formation of a single wide peak with

207 maximum UV absorbance corresponded to approximately 60S sedimentation coefficient, exactly 
208 between $70 \mathrm{~S}$ and 50S. At the same time, the 30S peak was increased, but to the less extent than

209 in case of the full dissociation promoted by IF3. The most logical explanation of this

210 phenomenon would be that Aim23p cannot promote the normal ribosome dissociation at

211 concentrations used in the experiment (20:1 molar ratio in relation to the ribosomes

212 concentration) but instead binds it and fixes this unusual state of ribosomes. The appearance of

213 this "60S state" might be linked somehow to the Aim23p slight toxicity for E.coli cells observed

214 by us (see Fig. 1B). It should be noted, finally, that such action of Aim23p on the bacterial

215 ribosomes is definitely mediated by its mitochondria-specific terminal extensions.

216 The same ribosomal fractions were analyzed for presence of recombinant proteins by

217 Western-blot hybridization. We used the home-made antibodies against 6-His-tagged

218 recombinant Aim23p, and, luckily, they had a significant cross-reactivity with the 6-His-tag

219 (data not shown). Thus, we were able to detect Aim23p, Aim23 $\Delta \mathrm{N} \Delta \mathrm{C}$, and IF3 since all

220 recombinant proteins used in our experiments were 6-His-tagged. Results of this experiment can

221 be found in Fig. 2B. E.coli IF3 was indeed detected only in 30S fractions while Aim23p version

222 without terminal extensions was not seen in either ribosomal fraction; instead, Aim $23 \Delta \mathrm{N} \Delta \mathrm{C}$ was

223 found in the very first fractions with no ribosomes. This explains the impossibility of

$224 \operatorname{Aim} 23 \Delta \mathrm{N} \Delta \mathrm{C}$ to promote dissociation of bacterial ribosomes: this protein binds neither $70 \mathrm{~S}$

225 ribosomes nor their separate subunits. Interestingly, full-size Aim23p behaves in all the contrary

226 way compared to its version lacking terminal extensions. This protein is detectable in nearly all

227 fractions containing ribosomes, either assembled or in the form of subunits. Maximum amount of

228 Aim $23 \mathrm{p}$ is bound to free $30 \mathrm{~S}$ subunits, and there is almost equal distribution of the protein

229 between fractions corresponding to $50 \mathrm{~S}$ and "60S" peaks. Such non-canonical manner of binding

230 ribosomes might be one of the reasons why Aim $23 p$ promotes formation of their "60S" state.

\section{"60S state" of E.coli ribosomes is not a stable structure}

233

The observed peak at $60 \mathrm{~S}$ zone of the sedimentation profile may be explained in at least two ways. First opportunity is that Aim23p binds E.coli ribosomes and causes changes in their structure so that their sedimentation coefficient decreases to $60 \mathrm{~S}$. Alternative explanation is that, upon Aim23p binding, the ribosomal subunits become more flexible relative to one another. This, in turn, allows their reciprocal movements without full dissociation. In this case, the 
239 observed 60S peak might reflect the changed dynamic equilibrium between associated and

240 dissociated states of the ribosome, rather than formation of a stable structure. In order to

241 distinguish between these two possibilities, we have repeated our ribosomes fractionation

242 experiment with additional cross-linking step (with the help of formaldehyde) after incubation

243 with proteins. We did not use Aim $23 \Delta \mathrm{N} \Delta \mathrm{C}$ here since this protein is unable to bind E.coli

244 ribosomes (Fig. 2A and B). The results of cross-linking experiment are presented in Fig. 2C.

245 After formaldehyde treatment, the sedimentation profiles of ribosomes incubated with Aim23p

246 or IF3 were almost identical, and there was no 60S peak of the Aim23p-bound ribosomes. If $60 \mathrm{~S}$

247 peak would reflect the formation of a stable ribosomal structure, this structure would be fixed by

248 cross-linking. Thus, our results clearly indicate that the observation of 60S peak is the

249 consequence of some dynamic processes caused by Aim23p binding. One may speculate that

250 these processes are the very first stages of $70 \mathrm{~S}$ ribosomes dissociation which cannot continue

251 normally due to the unusual manner of Aim23p interaction with the ribosomes.

252 After obtaining these intriguing results, we have decided to analyze the dose-dependency

253 of the Aim23p effect on E.coli ribosomes. The resulting profiles of ribosomes sedimentation

254 after adding Aim23p at different concentrations are presented at Fig. 3A. If Aim23p

255 concentration is 2.5 times more than in previously described experiment (i.e. 50:1 molar ratio in

256 relation to the ribosomes concentration), then the peak of "60S state" is almost not observed.

257 Instead, one can see a normal 50S peak which is slightly moved towards the increase of the

258 sedimentation coefficient. At the same time, the 30S peak is meaningfully increased relative to

259 the situation when the "60S state" is clearly observed. When Aim 23 p concentration is increased

260 twice more (up to 100:1 molar ratio in relation to the ribosomes concentration), the resulting

261 profile is identical to that in case of IF3 adding to ribosomes. One can hypothesize that these

262 results reflect the consecutive stages of 70 S ribosomes dissociation through "60S state" to free

$26330 \mathrm{~S}$ and 50S subunits.

264

Aim23p and E.coli IF3 act jointly to dissociate bacterial ribosomes in vitro.

267

The discovered "60S state" of bacterial ribosomes might be the result of the decreased

268

ribosome stability. In other words, the equilibrium of the dissociation reaction in this case may

269 be slightly shifted towards free subunits without full dissociation. This, in turn, means that such state of the ribosome should be subjected to dissociation easier than the normal 70S state. In 
270 order to check this hypothesis, we performed in vitro dissociation experiments with Aim $23 \mathrm{p}$ and

271 IF3 being simultaneously added to ribosomes. While Aim23p was added in concentration

272 sufficient for "60S state" fixation (10:1 molar ratio in relation to the ribosomes concentration;

273 see Fig. 3B), the amount of IF3 used was not enough for full ribosome dissociation (15:1 molar

274 ratio in relation to the ribosomes concentration). If both proteins were presented in the reaction

275 together (each at the same concentration as alone), the complete dissociation was detected. This

276 phenomenon could be explained as follows. If "60S state" appears as a result of Aim $23 p$ action,

277 the minimal amount of the free 30S subunits is immediately formed (this was also seen in our

278 previous experiments, see Fig.2A and 3A). Adding a little amount of the cognate IF3 leads to the

279 fixation of the $30 \mathrm{~S}$ subunits in their free state and further shifts the reaction equilibrium towards

280 the dissociated state of the ribosome. Thus, Aim23p and IF3 may act jointly to promote the

281 dissociation of the bacterial ribosomes. To verify this, we performed a Western-blot analysis of

282 the ribosomes fractions corresponding to the free subunits and to the whole ribosomes in

283 presence of Aim23p, or IF3, or both proteins together. The results are presented at Fig. 3C. IF3

284 in this experiment has been found to bind exclusively free 30S subunits but not 70S ribosomes,

285 exactly as expected. Aim23p, however, is detected both in free $30 \mathrm{~S}$ subunits and in the $70 \mathrm{~S}$

286 ribosomes fractions (which fits well to our results presented in Fig. 2B), and this does not

287 qualitatively depend on presence or absence of IF3 in the reaction. This explains well the joint

288 action of these two proteins resulting in the ribosomes dissociation which cannot be achieved

289 when using Aim23p and IF3 at the same concentrations separately.

protein interaction with $E$.coli ribosomes

\section{Molecular modeling points on the importance of Aim23p terminal extensions for}

294 Aim23p interact with bacterial ribosome and what is the role of its terminal extensions in such interaction? To shed light on this problem, we have performed molecular modeling.

Previously (Atkinson et al. 2012) sequence alignment of Aim23p with E.coli IF3 and

297 other orthologs has been done. On the base of this data, as well as the known structure of $30 \mathrm{~S}$ complex with the cognate IF3 (Pioletti et al. 2001), we have built the homology model of Aim23p complex with E.coli 30S ribosomal subunit with the help of Modeller 9.18 (script may be found in Supplementary Information). In the resulting model, Aim23p eventually has a long 
301 and extended N-terminal tail (Suppl. Fig.2). Size of this tail was comparable with size of 30S

302 subunit and model could not provide valuable information about $\mathrm{N}$-terminal extension function.

303 We have suggested that $\mathrm{N}$-terminal extension is somehow structured and have built the

304 corresponding model with Rosetta AbInitio protocol. From 18398 decoys of N-terminal

305 extension, top ten had alpha-helical structure with RMSD less than $10 \AA$. This observation

306 reflects the fact that $\mathrm{N}$-terminal extension does not possess certain spatial structure but probably

307 has mobile helical packaging. N-terminal extension model with best Rosetta score was used to

308 rebuild new homology model of 16S RNA and Aim23p complex. Resulting model has

309 surprisingly revealed strong interaction of $\mathrm{N}$-terminal extension with $\mathrm{C}$-terminal domain of

310 Aim23p core part and with long 3' terminal helix of 16S RNA. Additional distance restraints

311 between centers of mass from 15 to $40 \AA$ were applied to sample distance between Aim23p's N-

312 terminal extension and C-terminal domain. As a result, top models have confirmed interaction of

313 N-terminal extension with C-terminal domain, while interaction with 16S RNA does not look

314 favorable. Best models of packed C-terminal extension showed interaction with $\mathrm{N}$-terminal

315 domain. Thus, in silico modeling points to the possible mode of Aim23p interaction with 30S

316 subunit where the terminal extensions of the protein "press down" the core Aim23p part to the

317 ribosome. This may be the reason of the importance of Aim23p terminal extensions for binding

318 bacterial ribosomes (see Fig.2). The summary of molecular modeling is presented in Figure 4. sequence of Aim23p may complement to minimal extent the absence of AIM23 gene in yeast 323 (Kuzmenko et al. 2014) which is a strong evidence of Aim23p being bona fide initiation factor 3 324 in mitochondria. This finding is not surprising taking into account that bacterial enzymes may 325 often functionally substitute for their mitochondrial orthologues in the organelles. This, for 326 example, has been demonstrated for several aminoacyl-tRNA synthetases (Edwards \& Schimmel 327 1987) (Chiu et al. 2009) and for the proteins involved in Fe-S clusters formation (Kispal et al. 328 1999). In this work, we have performed "reverse" experiment and investigated if Aim23p is able 329 to substitute for cognate IF3 in E.coli cells. The cases of successful complementation of bacterial 330 proteins by their mitochondrial orthologues have been described remarkably rarer than the 331 opposite situations. However, mammalian mitochondrial initiation factor 2 has been shown to 
332 function in E.coli cells instead or two cognate factors at once, namely IF1 and IF2 (Gaur et al.

333 2008). Most probably, this is due to the short insertion domain of mammalian mtIF2 that is

334 believed to execute the function of IF1 in mitochondria. Moreover, in a recent work it has been

335 demonstrated that mammalian mtIF3, although not being able to fully substitute for IF3 in E.coli,

336 exhibits some functional activity in bacterial cells (Ayyub et al. 2018). Speaking about Aim23p,

337 this protein, as we have discovered in the present study, does not work as an initiation factor in

338 E.coli, independently of presence or absence of the terminal extensions. We used an

339 experimental system where cognate IF3 gene was disrupted in the bacterial genome but was

340 presented on the plasmid under the control of glucose-repressible promoter. Such promoters are

341 well known to leak if the amount of glucose is low. In our case, this allows the synthesis of

342 minimal amount of IF3 and weak growth of the bacterial culture after a dozen of hours of

343 incubation, when the main portion of glucose becomes utilized by bacterial cells (Fig. 1B).

344 Surprisingly, this weak growth is even slower in presence of full-size Aim23p when comparing

345 to Aim23p without terminal extensions. This means that these regions of Aim $23 p$ even make this

346 protein slightly toxic for bacterial cells. Interestingly, mammalian mtIF3 behaves quite

347 differently in E.coli. Full-size factor does not markedly affect the E.coli growth rate while

348 deletion of the N-terminal extension leads to the severe growth impairment (Ayyub et al. 2018).

349 However, to our opinion, these results should not be directly compared with the data presented in

350 this work. The main reason for this is the difference in the experimental systems. Ayyub and

351 colleagues used the mutant strain in which IF3 was devoid of first 55 amino acids and was

352 synthesized in normal quantities. Earlier, the same authors have shown that this truncated version

353 of IF3 is enough for E.coli survival and can perform all main functions of the factor (Ayyub et al.

354 2017). This means that the action of any mtIF3 version in such cells is somewhat additional to

355 the action of the cognate factor. On the contrary, our E.coli cells contained minimal amount of

356 wild-type IF3 synthesized from repressed but leaking promoter, and the quantity of Aim $23 p$

357 encoded in the plasmid was much higher. In this case, the heterologous factor influence on the

358 bacterial cells might be stronger than that discovered by Ayyub and colleagues.

359 The negative influence of Aim23p on E.coli cells, most probably, might realize via its

360 interaction with bacterial ribosomes. This is exactly what we have demonstrated in the present

361 work. In certain concentration range, Aim23p promotes the formation of a very unusual state of

362 E.coli ribosomes in vitro. Our results presented in Fig.2 and 3 indicate that this state is 
363 characterized by the partial fusion of 70S and 50S peaks. The maximum of absorbance at $260 \mathrm{~nm}$

364 in this case approximately corresponds to the $60 \mathrm{~S}$ sedimentation coefficient. We propose to call

365 it "60S state". To our current knowledge, such ribosome state has never been detected in vivo.

366 However, it was described in in vitro experiments (Morimoto 1969), notably at approximately

367 the same magnesium concentrations as we used in our work (10 $\mathrm{mM}$ vs $7 \mathrm{mM}$, respectively).

368 Morimoto used a term "60S component" and postulated that this was a new stable intermediate

369 of the subunits association reaction and that this intermediate was just "swollen 70S" (Morimoto

370 1969). Further investigations, however, have demonstrated that the sedimentation coefficient of

371 this "swollen 70S" depends on the centrifugation speed and on the initial 70S concentration

372 (Spirin 1971). This indicates that discussed $\sim 60$ S zone on the sedimentation pattern is the

373 consequence of the dynamic equilibrium of dissociation-association reaction rather that the

374 stationary ribosomal structure. In our work, we came to the same conclusion when treating "60S

375 state" with formaldehyde (Fig. 2C). Such treatment led to complete disappearance of the

376 corresponding peak showing that corresponding state of the ribosomes cannot be regarged as

377 stable strucrure.

378 In this work, the 60S peak on the ribosomes sedimentation profile has been for the very

379 first time detected after adding a protein to the ribosomes. Aim23p possesses this activity due to

380 its terminal extensions since we have not seen any changes in the ribosome sedimentation profile

381 when adding $\operatorname{Aim} 23 \Delta \mathrm{N} \Delta \mathrm{C}$ (Fig. 2A). In order to elucidate the role of terminal extensions, we

382 have performed molecular modeling of Aim23p complex with 30S. According to its results, the

383 direct interaction between terminal extensions of Aim23p (especially N-terminal one) and the

384 core protein part might take place. This probably makes Aim23p "fixed" on the small subunit

385 (see Fig.4). Interestingly, the similar effect of mammalian mtIF3 has been described with regard

386 to human mitochondrial ribosomes dissociation in vitro (Haque et al. 2008). Full-length mtIF3

387 promotes normal dissociation while using its truncated version without terminal extensions

388 causes the partial fusion of the 39S (large subunit) and 55S (whole mitoribosome) peaks. This

389 clearly indicates some abnormal dissociation.

390 In the present work, the "60S state" has been demonstrated to dissociate by increased

391 amount of Aim23p (Fig. 3A), or by a small amount of E.coli IF3 (Fig. 3B). The slight toxicity of

392 Aim23p for E.coli cells (see above, Fig. 1B) may be also explained by fixing the "60S state"

393 which dissociates poorly in presence of marginal IF3 quantities synthesized from leaking 
394 promoter. At the same time, the presence of even large amount of Aim23p in E.coli cells

395 together with the physiological amount of the cognate IF3 has no effect on bacterial viability, as

396 we could see when purifying recombinant Aim23p from wild-type E.coli cells (data not shown).

397 Even if "60S state" is fixed in such conditions, it might rapidly dissociate to the subunits with the

398 help of IF3 since this state might dissociate easier than 70S ribosomes (see Fig. 3B). This may be

399 also the case in the work of Ayyub and colleagues: having sufficient amounts of cognate E.coli

400 IF3 allows bacterial ribosomes to keep the dissociated state in vivo properly regardless on the

401 mammalian mtIF3 presence, and this could explain almost normal growth of the corresponding

402 bacterial strains (Ayyub et al. 2018).

403 The question if "60S state" exists in wild-type bacterial cells is of high interest. The

404 answer "no" seems to be obvious as bacterial IF3 is well-known to bind only free 30S subunits.

405 This was also seen in the present work (Fig. 2B and 3C). At the same time, IF3 must bind 70S

406 ribosomes, or at least keep bound to $30 \mathrm{~S}$ when $70 \mathrm{~S}$ is already formed, to fix any dissociation

407 intermediate. The impossibility of this binding, however, is not dogmatic. In the structural study,

408 IF3 was found as a part of the fully assembled bacterial initiator complex, together with 70S

409 ribosomes (Allen et al. 2005). The authors propose that IF3 does bind the free 30S subunit

410 initially and then remains bound to $70 \mathrm{~S}$ ribosomes for a short time after subunits association.

411 Moreover, in a recent study binding of IF3 with 70S ribosome was confirmed by FRET

412 experiments, and an alternative binding site of IF3 was identified on 50S subunit (Goyal et al.

413 2017). The subunits association in presence of IF3 might be realized via some intermediate states

414 relative to the "60S state" detected in the present work.

415 The possible mechanisms of the E.coli ribosomes $60 \mathrm{~S}$ intermediate state formation and

416 dissociation are summarized in Fig.5.

417

418

CONCLUSIONS

419

The main result of this work is the detection of a state of E.coli ribosomes ("60S state")

420 which is formed as a result of interaction with S.cerevisiae mitochondrial translation initiation

421 factor 3, Aim23p. We also demonstrate that Aim23p and cognate E.coli IF3 actions on bacterial

422 ribosome are of different modes and that these two proteins may bind it jointly. We show that the

423 key players in the game of Aim23p binding to E.coli ribosomes are protein's mitochondria-

424 specific terminal extensions that, according to the molecular modeling results, might nestle the 
425 core part of Aim23p to ribosomal small subunit. Thus, the binding efficiency increases. Our 426 results provide a basis for future structural studies of "60S state" which, in turn, will elucidate 427 the fine mechanisms of bacterial ribosome dissociation / association.

428

429

430

431

432

433

434

435

436

437

438

439

440

441

442

443

444

445

446

447

448

449

450

451

452

453

454

455

\section{ACKNOWLEDGEMENTS}

We are grateful to Gemma Atkinson (Umea University, Sweden, and Tartu University, Estonia) for the in silico prediction of Aim23p terminal extensions. We also thank Konstantin Khodosevich (Copenhagen University, Denmark), Vasili Hauryliuk (Umea University, Sweden, and Tartu University, Estonia), Ivan Tarassov (Strasbourg University, France), Stanislav Kozlovsky and Alexey Kharitonov (Moscow University, Russia) for providing strains and chemicals. We appreciate the improvement of the figures quality by Alexey Fedyakov (Moscow University, Russia). Our special thanks are to Sergey Dmitriev (Moscow University, Russia) and to Vyacheslav Kolb and his lab members (Institute of Protein Research, Russia) for helpful discussions. The technical help of our students Maria Klimontova, Valeria Zinina, Anna Mirnaya, Anastasia Kapusta, and Margarita Chudenkova is greatly appreciated.

\section{REFERENCES}

Allen GS, Zavialov A, Gursky R, Ehrenberg M, and Frank J. 2005. The cryo-EM structure of a translation initiation complex from Escherichia coli. Cell 121:703-712. DOI 10.1016/j.cell.2005.03.023.

Atkinson GC, Kuzmenko A, Kamenski P, Vysokikh MY, Lakunina V, Tankov S, Smirnova E, Soosaar A, Tenson T, and Hauryliuk V. 2012. Evolutionary and genetic analyses of mitochondrial translation initiation factors identify the missing mitochondrial IF3 in S. cerevisiae. Nucleic Acids Res 40:6122-6134. DOI 10.1093/nar/gks272

Ayyub SA, Dobriyal D, and Varshney U. 2017. Contributions of the N- and C-Terminal Domains of Initiation Factor 3 to Its Functions in the Fidelity of Initiation and Antiassociation of the Ribosomal Subunits. J Bacteriol 199. DOI 10.1128/JB.00051-17

Ayyub SA, Dobriyal D, Aluri S, Spremulli LL, and Varshney U. 2018. Fidelity of translation in the presence of mammalian mitochondrial initiation factor 3. Mitochondrion 39:18. DOI 10.1016/j.mito.2017.08.006 
456

457

458

459

460

461

462

463

464

465

466

467

468

469

470

471

472

473

474

475

476

477

478

479

480

481

482

483

484

Bonneau R, Strauss CE, Rohl CA, Chivian D, Bradley P, Malmstrom L, Robertson T, and Baker D. 2002. De novo prediction of three-dimensional structures for major protein families. $J$ Mol Biol 322:65-78.

Bonneau R, Tsai J, Ruczinski I, Chivian D, Rohl C, Strauss CE, and Baker D. 2001. Rosetta in CASP4: progress in ab initio protein structure prediction. Proteins Suppl 5:119-126. DOI 10.1002/prot.1170

Chiu WC, Chang CP, and Wang CC. 2009. Evolutionary basis of converting a bacterial tRNA synthetase into a yeast cytoplasmic or mitochondrial enzyme. J Biol Chem 284:2395423960. DOI 10.1074/jbc.M109.031047

Edwards H, and Schimmel P. 1987. An E. coli aminoacyl-tRNA synthetase can substitute for yeast mitochondrial enzyme function in vivo. Cell 51:643-649.

Gaur R, Grasso D, Datta PP, Krishna PD, Das G, Spencer A, Agrawal RK, Spremulli L, and Varshney U. 2008. A single mammalian mitochondrial translation initiation factor functionally replaces two bacterial factors. Mol Cell 29:180-190. DOI 10.1016/j.molcel.2007.11.021

Goss DJ, Parkhurst LJ, and Wahba AJ. 1980. Kinetics of ribosome dissociation and subunit association. The role of initiation factor IF3 as an effector. J Biol Chem 255:225-229. Gottleib M, Davis BD, and Thompson RC. 1975. Mechanism of dissociation of ribosomes of Escherichia coli by initiation factor IF-3. Proc Natl Acad Sci U S A 72:4238-4242. Goyal A, Belardinelli R, and Rodnina MV. 2017. Non-canonical Binding Site for Bacterial Initiation Factor 3 on the Large Ribosomal Subunit. Cell Rep 20:3113-3122. DOI 10.1016/j.celrep.2017.09.012

Gualerzi C, Risuleo G, and Pon CL. 1977. Initial rate kinetic analysis of the mechanism of initiation complex formation and the role of initiation factor IF-3. Biochemistry 16:1684-1689. Haque ME, Grasso D, and Spremulli LL. 2008. The interaction of mammalian mitochondrial translational initiation factor 3 with ribosomes: evolution of terminal extensions in IF3mt. Nucleic Acids Res 36:589-597. DOI 10.1093/nar/gkm1072

Kim DE, Chivian D, and Baker D. 2004. Protein structure prediction and analysis using the Robetta server. Nucleic Acids Res 32:W526-531. DOI 10.1093/nar/gkh468 
485

486

487

488

489

490

491

492

493

494

495

496

497

498

499

500

501

502

503

504

505

506

507

508

509

510

511

512

513

514

515

Kispal G, Csere P, Prohl C, and Lill R. 1999. The mitochondrial proteins Atm1p and $\mathrm{Nfs} 1 \mathrm{p}$ are essential for biogenesis of cytosolic Fe/S proteins. EMBO J 18:3981-3989. DOI 10.1093/emboj/18.14.3981

Kleiger G, Saha A, Lewis S, Kuhlman B, and Deshaies RJ. 2009. Rapid E2-E3 assembly and disassembly enable processive ubiquitylation of cullin-RING ubiquitin ligase substrates. Cell 139:957-968. DOI 10.1016/j.cell.2009.10.030

Kuzmenko A, Atkinson GC, Levitskii S, Zenkin N, Tenson T, Hauryliuk V, and

Kamenski P. 2014. Mitochondrial translation initiation machinery: conservation and diversification. Biochimie 100:132-140. DOI 10.1016/j.biochi.2013.07.024

Laursen BS, Sorensen HP, Mortensen KK, and Sperling-Petersen HU. 2005. Initiation of protein synthesis in bacteria. Microbiol Mol Biol Rev 69:101-123. DOI

10.1128/MMBR.69.1.101-123.2005

Morimoto T. 1969. Intermediate stage in the association and dissociation of Escherichia coli ribosomes and the combining properties of their subunits. Biochim Biophys Acta 182:135146.

Peske F, Rodnina MV, and Wintermeyer W. 2005. Sequence of steps in ribosome recycling as defined by kinetic analysis. Mol Cell 18:403-412. DOI

10.1016/j.molcel.2005.04.009

Pioletti M, Schlunzen F, Harms J, Zarivach R, Gluhmann M, Avila H, Bashan A, Bartels H, Auerbach T, Jacobi C, Hartsch T, Yonath A, and Franceschi F. 2001. Crystal structures of complexes of the small ribosomal subunit with tetracycline, edeine and IF3. EMBO J 20:18291839. DOI 10.1093/emboj/20.8.1829

Rivera MC, Maguire B, and Lake JA. 2015. Isolation of ribosomes and polysomes. Cold Spring Harb Protoc 2015:293-299. DOI 10.1101/pdb.prot081331

Sali A, and Blundell TL. 1993. Comparative protein modelling by satisfaction of spatial restraints. J Mol Biol 234:779-815. DOI 10.1006/jmbi.1993.1626

Spirin AS. 1971. On the equilibrium of the association-dissociation reaction of ribosomal subparticles and on the existance of the so-called '60 S intermediate' ('swollen $70 \mathrm{~S}$ ') during centrifugation of the equilibrium mixture. FEBS Lett 14:349-353.

Thomason LC, Costantino N, and Court DL. 2007. E. coli genome manipulation by P1 transduction. Curr Protoc Mol Biol Chapter 1:Unit 1. DOI 10.1002/0471142727.mb0117s79 
Wertheimer SJ, Klotsky RA, and Schwartz I. 1988. Transcriptional patterns for the thrS-

517 infC-rplT operon of Escherichia coli. Gene 63:309-320.

518 Zavialov AV, Hauryliuk VV, and Ehrenberg M. 2005. Splitting of the posttermination

519 ribosome into subunits by the concerted action of RRF and EF-G. Mol Cell 18:675-686. DOI

$520 \quad 10.1016 /$ j.molcel.2005.05.016

521

522

523

\section{FIGURE LEGENDS}

524

Fig.1. Aim23p without terminal extensions is non-functional in E.coli cells while fullsize Aim23p is even slightly toxic. (A) Scheme of the mutant E.coli strains production. At the first stage, the infC gene coded for E.coli IF3 was cloned into pACDH vector. The resulting plasmid was delivered into E.coli cells following by the genomic disruption of infC by the chloramphenicol resistance gene (Cat). The infC gene on the plasmid made the resulting strain viable. Then, the cells were inoculating by P1 phage in order to capture the genomic DNA region containing the disrupted infC gene. The result of the first stage was the phage with the abovementioned genomic DNA region. On the second stage, the infC gene was cloned into pBAD vector (under control of glucose-repressible promoter), and genes of Aim $23 \mathrm{p}$ and Aim $23 \Delta \mathrm{N} \Delta \mathrm{C}$ were cloned into pACDH vector. pBAD-infC and pACDH with one of the above-mentioned genes were then delivered into wild-type E.coli cells following by the inoculation by the phage from the first stage. This was resulted in the substitution of the wild-type infC genomic copy by the disrupted gene. As a result, a series of E.coli strains were generated with the following features: (1) genomic disruption of infC, (2) presence of infC on the pBAD vector, (3) presence of infC (positive control), Aim23p, or Aim $23 \Delta \mathrm{N} \Delta \mathrm{C}$ on the pACDH vector. (B) Growth curves of the E.coli strains (indicated on the right) obtained as described in Fig. 3A. Bacteria were initially incubated without glucose, then the medium was changed to the glucose-containing one, and the optical density registration began. Each strain contained infC gene on the pBAD vector under control of glucose-repressible promoter. IF3: infC gene on the pACDH vector. Vector: empty pACDH. Aim23 and Aim23 $\Delta \mathrm{N} \Delta \mathrm{C}$ : full-size and truncated AIM23 genes, respectively, on the pACDH vector. 
Fig. 2. The unusual effects of Aim23p on E.coli ribisomes in vitro. (A, C) Ribosomes

548

549

550

551

552

553

554

555

556

557

558

559

560

561

562

563

564

565

566

567

568

569

570

571

572

573

574

575

576 sedimentation profiles: optical densities at $260 \mathrm{~nm}$ (Y-axes of the graph) of different fractions of E.coli ribosomes which were pre-incubated with the indicated proteins, cross-linked with formaldehyde (C) or not (A), and sedimented in the sucrose gradient. On the X-axes: 20-25 sequential fractions, from bottom to top of the gradient. Molar ratios protein:ribosomes are indicated near each sedimentation profile. The peaks corresponded to the ribosomes and their free subunits are marked with the vertical dotted lines. (B) Western-blot hybridization of different fractions of E.coli ribisomes pre-incubated with different proteins. The same ribosomes samples as in (A) were analyzed for this experiment. We used the antibodies against recombinant Aim23p with the significant cross-reactivity to the 6-His-tag which allowed us to detect both Aim23p and IF3. Numbers of fractions analyzed are indicated below. LC: loading control.

Fig. 3. Aim23p is able to dissociate E.coli ribisomes either in large concentrations, or together with E.coli IF3. (A, B) Ribosomes sedimentation profiles: optical densities at $260 \mathrm{~nm}$ (Y-axes of the each graph) of different fractions of E.coli ribosomes which were pre-incubated with the indicated proteins and sedimented in the sucrose gradient. On the X-axes: 20-25 sequential fractions, from bottom to top of the gradient. Molar ratios protein:ribosomes are indicated near each sedimentation profile. The peaks corresponded to the ribosomes and their free subunits are marked with the vertical dotted lines. (C) Western-blot hybridization of different fractions of E.coli ribosomes which were pre-incubated with the indicated proteins and sedimented in the sucrose gradient. In each case, the mixture of 2 fractions composing the peaks of $30 \mathrm{~S}$ or $70 \mathrm{~S}$ was analyzed (indicated on the top). 2 fractions composing the corresponding peaks on Fig. 3B were combined and loaded on PAAG. We used the antibodies against recombinant Aim23p with the significant cross-reactivity to the 6-His-tag which allowed us to detect both Aim23p and IF3 (indicated by arrows on the left) in the single analysis.

Fig. 4. Model of Aim23p interactions with E.coli 16S RNA. N-terminal extension is in light-pink, N-terminal domain is in hot-pink, C-terminal domain is in magenta and C-terminal extension is in deep-purple. 16S RNA is in black and white. (A) Overview of Aim23p location on 16S RNA. (B) Close-up view in same orientation. (C) Close-up view with counterclockwise 
577 rotation around vertical axis displaying proximity of $\mathrm{N}$-terminal extension, $\mathrm{C}$-terminal domain 578 and 16S RNA.

579

$580 \quad$ Fig.5. The hypothetic scheme of the formation and dissociation of E.coli ribosomes

581 intermediate state in vitro. 1. Initially, the small (SSU) and large (LSU) subunits of the ribosome

582 are associated one to another (70S). Adding of Aim23p (the terminal extensions are represented

583 by black boxes) changes the ribosome conformation making the subunits more flexible relative

584 to one another and allowing their reciprocal movements without full dissociation (60S). 2. This

585 intermediate dissociation state cannot spontaneously dissociate to the subunits in presence of

586 Aim23p. 3. Adding more Aim23p, however, shifts the dissociation reaction equilibrium which

587 results in appearance of the free SSU and LSU $(30 \mathrm{~S}+50 \mathrm{~S})$. 4. Full dissociation of the

588 intermediate can also be reached by adding E.coli IF3 in amount insufficient for dissociation of

$58970 \mathrm{~S}$ ribosomes. 


\section{Figure 1}

Aim23p without terminal extensions is non-functional in E.coli cells while full-size Aim23p is even slightly toxic.

(A) Scheme of the mutant E.coli strains production. At the first stage, the infC gene coded for E.coli IF3 was cloned into PACDH vector. The resulting plasmid was delivered into E.coli cells following by the genomic disruption of infC by the chloramphenicol resistance gene (Cat). The infC gene on the plasmid made the resulting strain viable. Then, the cells were inoculating by P1 phage in order to capture the genomic DNA region containing the disrupted infC gene. The result of the first stage was the phage with the above-mentioned genomic DNA region. On the second stage, the infC gene was cloned into pBAD vector (under control of glucose-repressible promoter), and genes of Aim23p and Aim23 $\triangle N \Delta C$ were cloned into pACDH vector. PBAD-infC and PACDH with one of the above-mentioned genes were then delivered into wild-type E.coli cells following by the inoculation by the phage from the first stage. This was resulted in the substitution of the wild-type infC genomic copy by the disrupted gene. As a result, a series of E.coli strains were generated with the following features: (1) genomic disruption of infC, (2) presence of infC on the pBAD vector, (3) presence of infC (positive control), Aim23p, or Aim23 $\triangle N \Delta C$ on the pACDH vector. (B) Growth curves of the E.coli strains (indicated on the right) obtained as described in Fig. 3A. Bacteria were initially incubated without glucose, then the medium was changed to the glucosecontaining one, and the optical density registration began. Each strain contained infC gene on the PBAD vector under control of glucose-repressible promoter. IF3: infC gene on the pACDH vector. Vector: empty pACDH. Aim23 and Aim23 NNAC: full-size and truncated AIM23 genes, respectively, on the PACDH vector. 

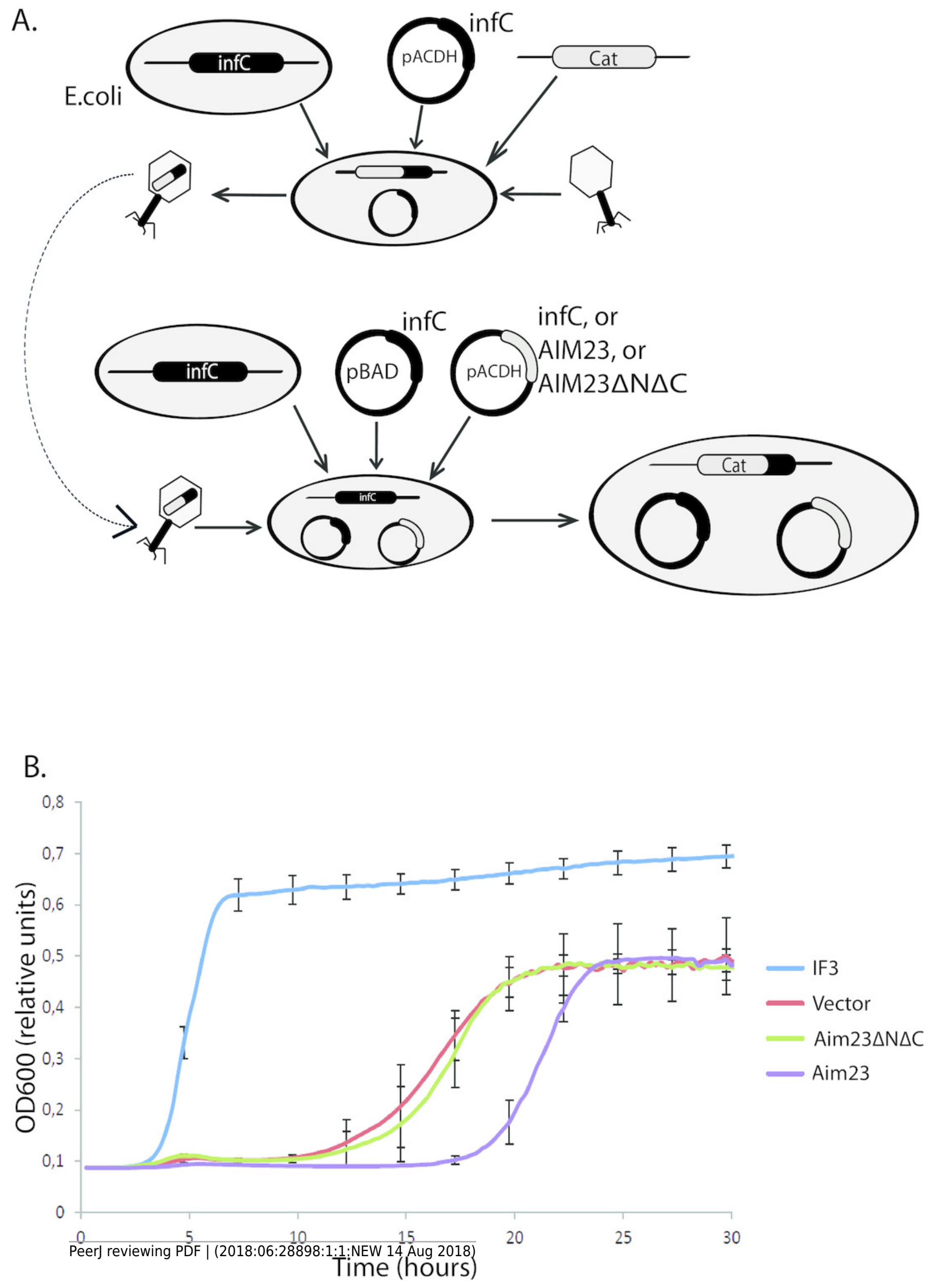


\section{Figure 2}

The unusual effects of Aim23p on E.coli ribosomes in vitro.

(A, C) Ribosomes sedimentation profiles: optical densities at $260 \mathrm{~nm}$ (Y-axes of the graph) of different fractions of E.coli ribosomes which were pre-incubated with the indicated proteins, cross-linked with formaldehyde $(\mathrm{C})$ or not $(\mathrm{A})$, and sedimented in the sucrose gradient. On the $X$-axes: 20-25 sequential fractions, from bottom to top of the gradient. Molar ratios protein:ribosomes are indicated near each sedimentation profile. The peaks corresponded to the ribosomes and their free subunits are marked with the vertical dotted lines. (B) Westernblot hybridization of different fractions of E.coli ribosomes pre-incubated with different proteins. The same ribosomes samples as in (A) were analyzed for this experiment. We used the antibodies against recombinant Aim23p with the significant cross-reactivity to the 6-Histag which allowed us to detect both Aim23p and IF3. Numbers of fractions analyzed are indicated below. LC: loading control. 
A.

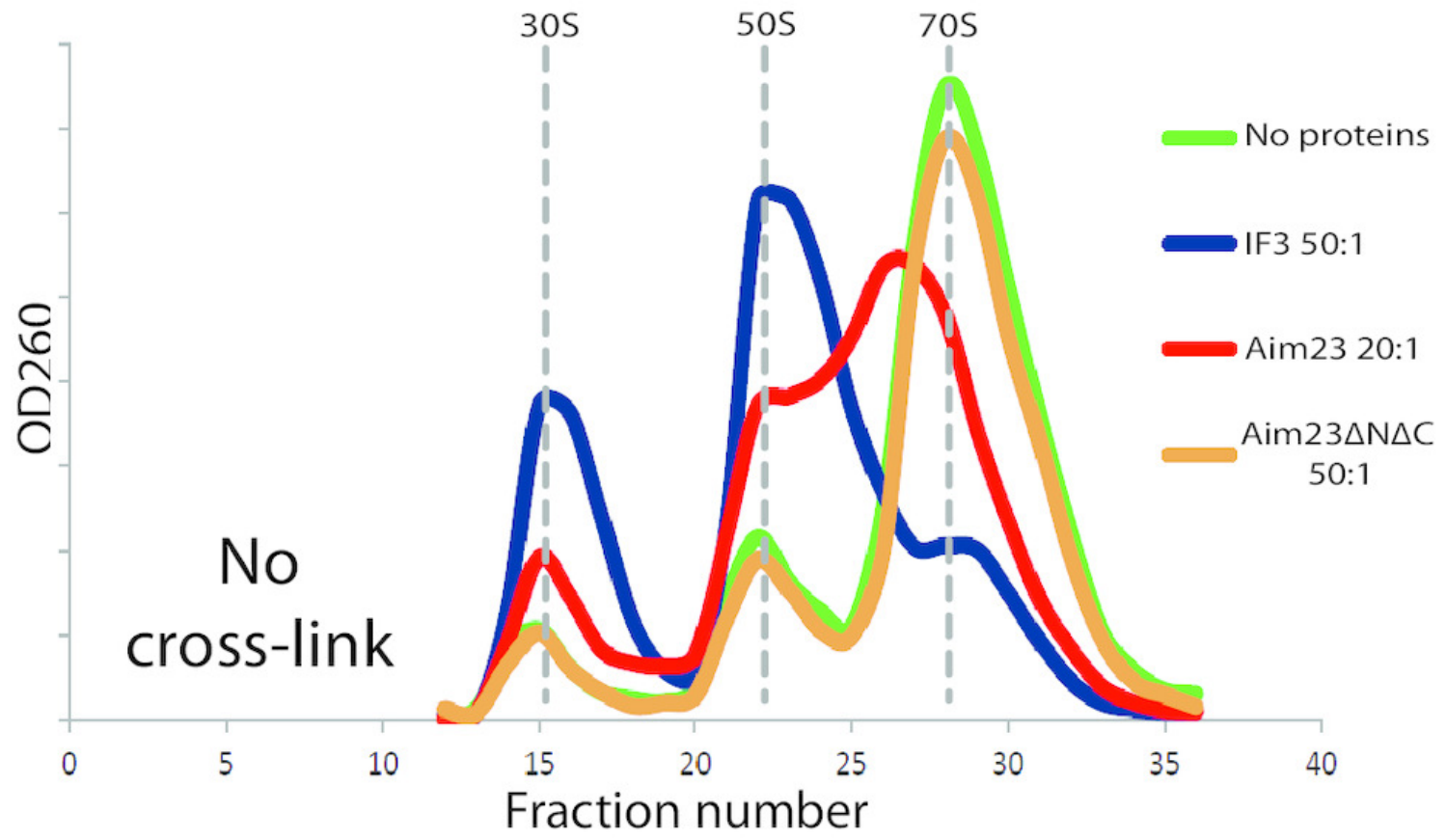

B.
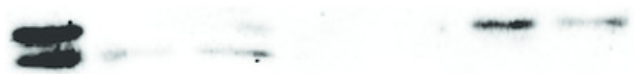

IF3
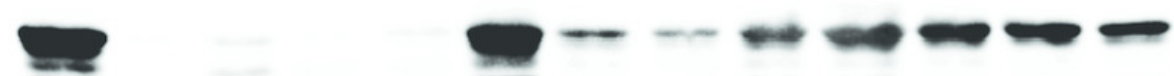

Aim 23
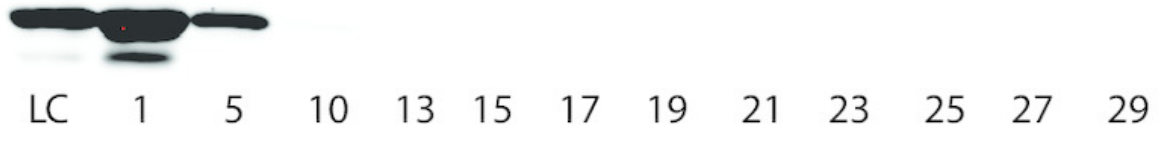

31

C.

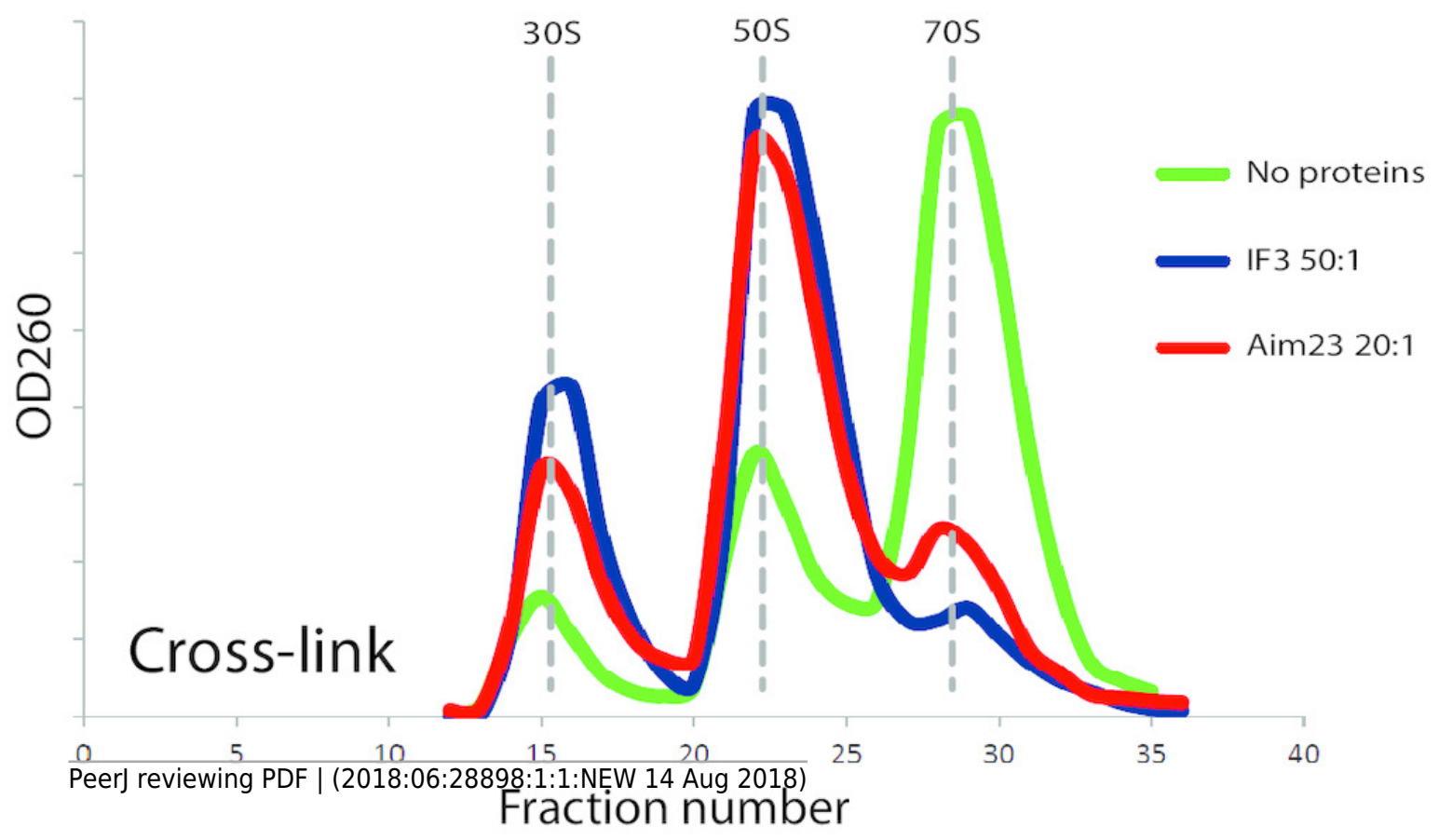




\section{Figure 3}

Aim23p is able to dissociate E.coli ribosomes either in large concentrations, or together with E.coli IF3.

(A, B) Ribosomes sedimentation profiles: optical densities at $260 \mathrm{~nm}$ (Y-axes of the each graph) of different fractions of E.coli ribosomes which were pre-incubated with the indicated proteins and sedimented in the sucrose gradient. On the X-axes: 20-25 sequential fractions, from bottom to top of the gradient. Molar ratios protein:ribosomes are indicated near each sedimentation profile. The peaks corresponded to the ribosomes and their free subunits are marked with the vertical dotted lines. (C) Western-blot hybridization of different fractions of E.coli ribosomes which were pre-incubated with the indicated proteins and sedimented in the sucrose gradient. In each case, the mixture of 2 fractions composing the peaks of $30 \mathrm{~S}$ or $70 \mathrm{~S}$ was analyzed (indicated on the top). 2 fractions composing the corresponding peaks on Fig. 3B were combined and loaded on PAAG. We used the antibodies against recombinant Aim23p with the significant cross-reactivity to the 6-His-tag which allowed us to detect both Aim23p and IF3 (indicated by arrows on the left) in the single analysis. 
A.

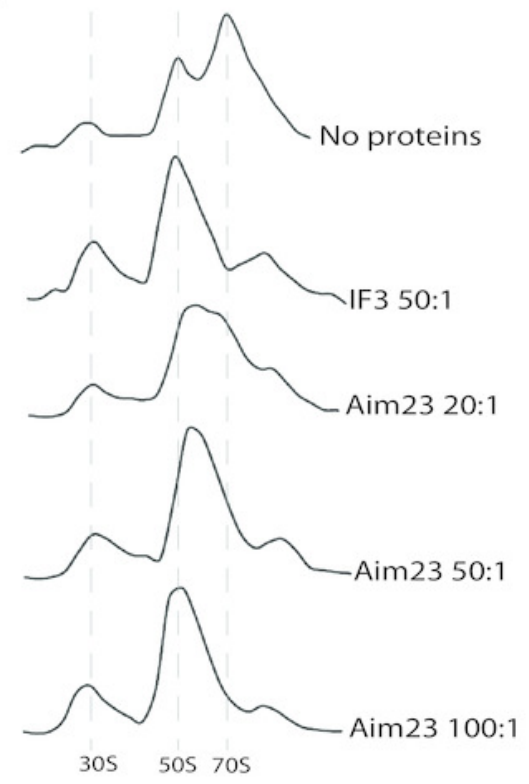

B.

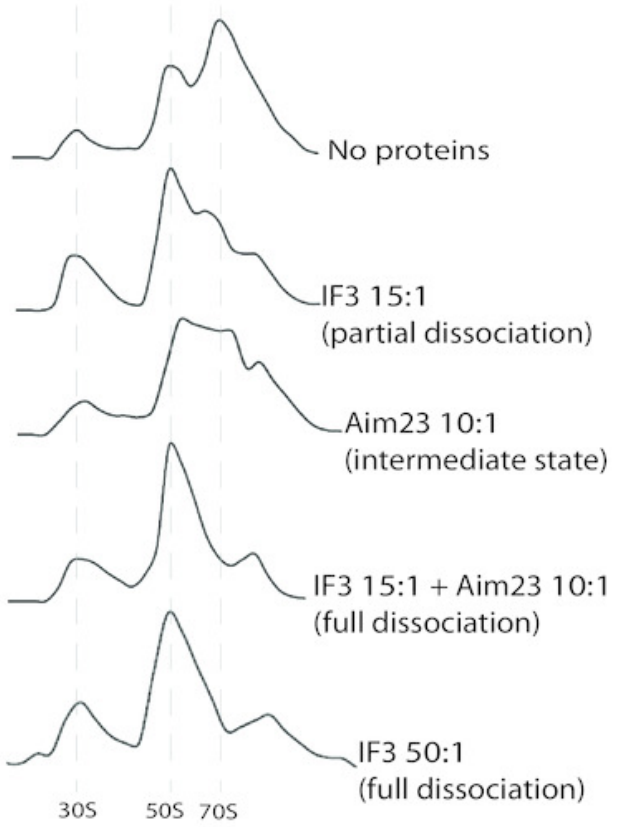

C.

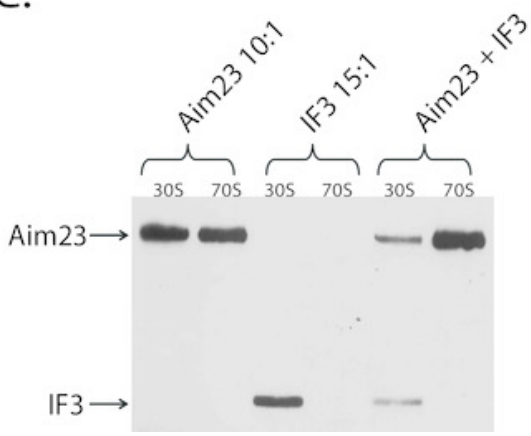




\section{Figure 4}

Model of Aim23p interactions with E.coli 16S RNA.

$\mathrm{N}$-terminal extension is in light-pink, N-terminal domain is in hot-pink, C-terminal domain is in magenta and C-terminal extension is in deep-purple. 16S RNA is in black and white. (A) Overview of Aim23p location on 16S RNA. (B) Close-up view in same orientation. (C) Closeup view with counterclockwise rotation around vertical axis displaying proximity of $\mathrm{N}$ terminal extension, C-terminal domain and 16S RNA.

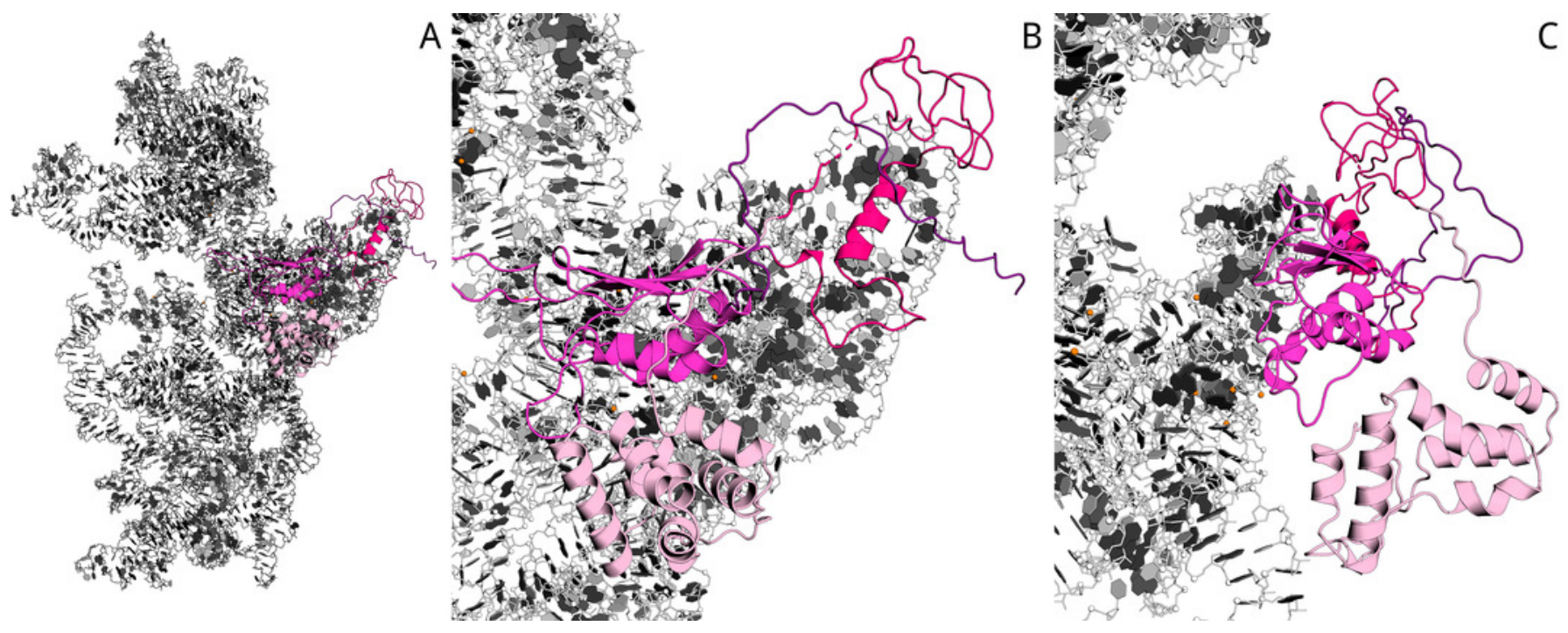




\section{Figure 5}

The hypothetic scheme of the formation and dissociation of E.coli ribosomes intermediate state in vitro.

1. Initially, the small (SSU) and large (LSU) subunits of the ribosome are associated one to another (70S). Adding of Aim23p (the terminal extensions are represented by black boxes) changes the ribosome conformation making the subunits more flexible relative to one another and allowing their reciprocal movements without full dissociation (60S). 2. This intermediate dissociation state cannot spontaneously dissociate to the subunits in presence of Aim23p. 3. Adding more Aim23p, however, shifts the dissociation reaction equilibrium which results in appearance of the free SSU and LSU $(30 S+50 S)$. 4. Full dissociation of the intermediate can also be reached by adding E.coli IF3 in amount insufficient for dissociation of 705 ribosomes. 


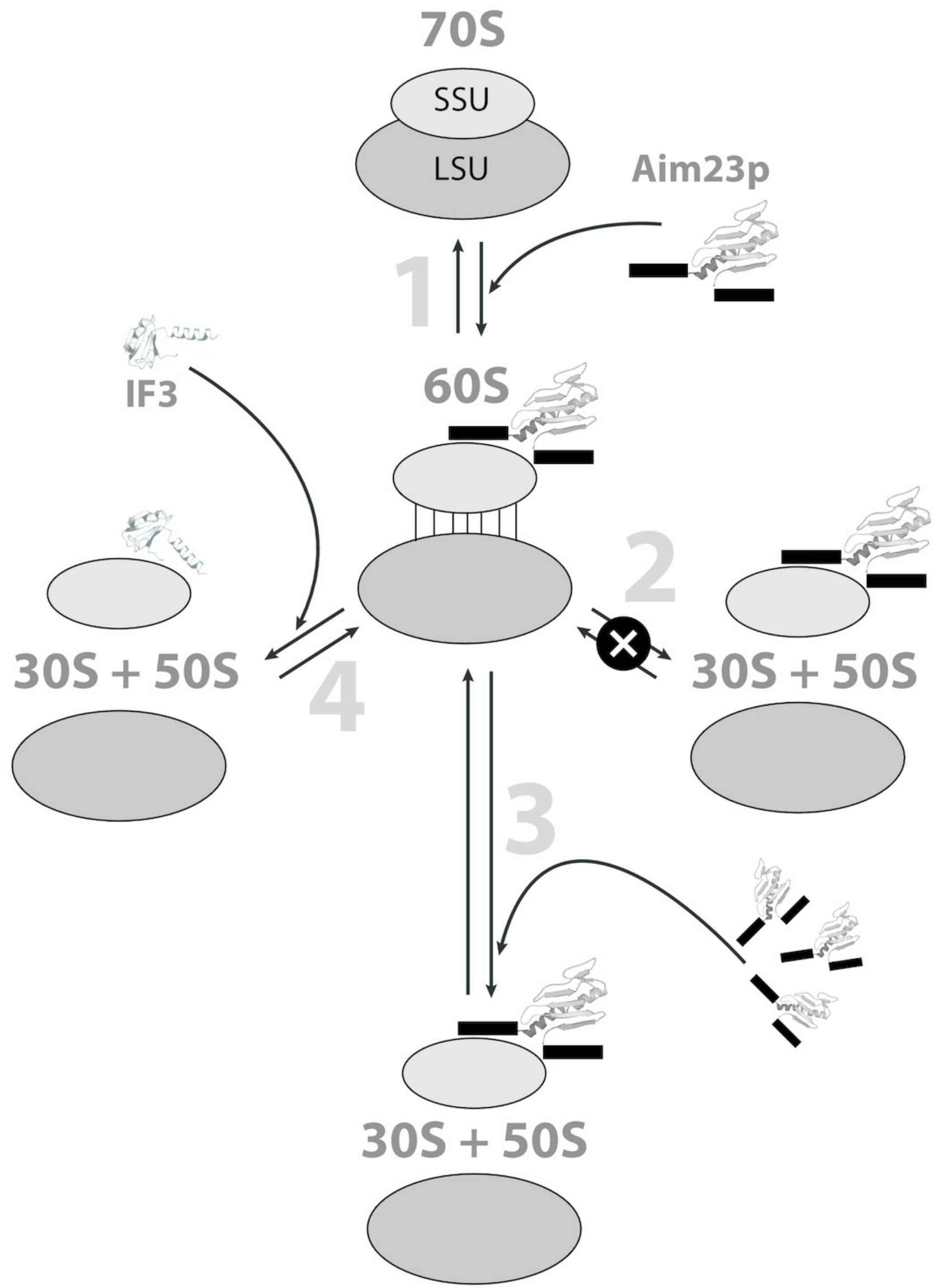




\section{Table $\mathbf{1}$ (on next page)}

Plasmids used in this work. 
Table 1. Plasmids used in the work

\begin{tabular}{|c|c|}
\hline Plasmid & Description \\
\hline pACDH & Low-copy vector for expression in E.coli \\
\hline pACDHinfC* & pACDH with cloned infC gene from E.coli \\
\hline pACDHAim 23* & $\begin{array}{l}\text { pACDH with cloned AIM } 23 \text { gene lacking mitochondrial targeting } \\
\text { sequence }\end{array}$ \\
\hline pACDHAim $23 \Delta \mathrm{N} \Delta \mathrm{C}^{*}$ & $\begin{array}{l}\text { pACDH with cloned AIM } 23 \text { gene lacking mitochondrial targeting } \\
\text { sequence and both terminal extensions }\end{array}$ \\
\hline pBAD & Vector for E.coli expression containing glucose-repressible promoter \\
\hline pBADinfC* & pBAD with cloned infC gene from E.coli \\
\hline pKD3 & $\begin{array}{l}\text { Plasmid containing FRT-cat-FRT for preparation of E.coli disruption } \\
\text { cassettes }\end{array}$ \\
\hline pKD46 & $\begin{array}{l}\text { Plasmid with Lambda Red recombinase from phage } \lambda \text { for efficient } \\
\text { gene disruption in E.coli }\end{array}$ \\
\hline pET32a & Vector for the heterologous proteins expression in E.coli \\
\hline pETIF3* & pET32a with cloned infC gene from E.coli \\
\hline pETAim23* & $\begin{array}{l}\text { pET32a with cloned AIM23 gene lacking mitochondrial targeting } \\
\text { sequence }\end{array}$ \\
\hline pETAim $23 \Delta \mathrm{N} \Delta \mathrm{C}^{*}$ & $\begin{array}{l}\text { pET32a with cloned AIM23 gene lacking mitochondrial targeting } \\
\text { sequence and both terminal extensions }\end{array}$ \\
\hline
\end{tabular}

2

* Generated in this work. 


\section{Table 2 (on next page)}

E.coli strains used in this work. 
Table 2. E.coli strains used in the work

\begin{tabular}{|c|c|}
\hline Strain & Genotype / Description / Purpose \\
\hline MG 1655 & $\begin{array}{l}\mathrm{K}-12 \mathrm{~F}^{-} \lambda^{-} \mathrm{ilvG} \mathrm{G}^{-} \mathrm{rfb}-50 \mathrm{rph}-1 \\
\text { For genetic manipulations, for ribosome isolation }\end{array}$ \\
\hline MG_infC_ACDH* & MG $1655+$ pACDHinfC + pKD46 \\
\hline$\overline{\mathrm{MG} \_\Delta \mathrm{IF} 3 *}$ & $\begin{array}{l}\text { MG_infC_ACDH with first } 153 \text { nucleotides of inf3 gene } \\
\text { exchanged by chloramphenicol resistance cassette }\end{array}$ \\
\hline $\begin{array}{l}\text { MG_infC_BAD* } \\
\text { ("vector" on Fig.3) }\end{array}$ & MG $1655+$ pBADinfC + pACDH \\
\hline $\begin{array}{l}\text { MG_IF3* } \\
\text { (“IF3"'on Fig.3) }\end{array}$ & MG $1655+$ pBADinfC + pACDHinfC \\
\hline $\begin{array}{r}\text { MG_Aim23* } \\
\text { ("Aim23”on Fig.3) }\end{array}$ & MG $1655+$ pBADinfC + pACDHAim 23 \\
\hline 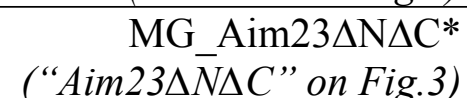 & MG $1655+$ pBADinfC + pACDHAim $23 \Delta N \Delta C$ \\
\hline Rosetta (DE3) pLysS & $\begin{array}{l}\mathrm{F}^{-} \text {ompT hsdS } \mathrm{B}_{\mathrm{B}}\left(\mathrm{R}_{\mathrm{B}}{ }^{-} \mathrm{m}_{\mathrm{B}}{ }^{-}\right) \text {gal dcm } \lambda(\mathrm{DE} 3 \text { [lacI lacUV5- } \\
\mathrm{T} 7 \text { gene } 1 \text { ind1 sam7 nin5]) pLysSRARE }\left(\mathrm{Cam}^{\mathrm{R}}\right) \\
\text { For heterologous proteins synthesis and purification }\end{array}$ \\
\hline Top10 & $\begin{array}{l}\text { F- mcrA } \Delta(\text { mrr-hsdRMS-mcrBC) } \varphi 801 \text { lacZ } \Delta \text { M15 } \Delta \text { lacX74 nupG } \\
\text { recA1 araD139 } \Delta \text { (ara-leu)7697 galE15 galK16 } \operatorname{rpsL}\left(\operatorname{Str}^{\mathrm{R}}\right) \text { endA1 } \\
\lambda^{-} \\
\text {For molecular cloning }\end{array}$ \\
\hline
\end{tabular}

2

* Generated in this work. 


\section{Table $\mathbf{3}$ (on next page)}

Oligonucleotides used in this work. 


\section{Table 3. Oligonucleotides used in the work}

2 (all synthesized by Evrogen)

3 Restriction sites are in capital letters.

\begin{tabular}{|c|c|c|}
\hline 1 & \multirow{2}{*}{$\begin{array}{l}\text { Cloning of IF3 into pACDH and } \\
\text { pBAD }\end{array}$} & tcagccatggctaaaggcggaaaacgagttc \\
\hline 2 & & tcaggaattcctactgtttcttcttaggagcga \\
\hline 3 & \multirow{2}{*}{$\begin{array}{l}\text { Cloning of AIM } 23 \Delta \mathrm{N} \Delta \mathrm{C} \text { into } \\
\text { pACDH }\end{array}$} & tcagccatggcttggagcaccgggaca \\
\hline 4 & & tcaggaattcctatggtttaacgtcctttggta \\
\hline 5 & \multirow{2}{*}{ Cloning of AIM23 into pACDH } & tcagccatggctaatgcatcatctaccacag \\
\hline 6 & & tcaggaattcctacatttcattcattttttttctctg \\
\hline 7 & \multirow{2}{*}{$\begin{array}{l}\text { Production of chloramphenicol } \\
\text { resistance disruption cassette }\end{array}$} & $\begin{array}{l}\text { tgcaacaagagattcgcagccgcagtcttaaacaattggaggaataaggtatgg } \\
\text { agaaaaaaatcactgg }\end{array}$ \\
\hline 8 & & $\begin{array}{l}\text { ccattatacgacaaaccggcggetcggegttagggetgatctcgactaagtcatc } \\
\text { gcagtactgttgta }\end{array}$ \\
\hline 9 & \multirow{2}{*}{$\begin{array}{l}\text { Screening of IF3 disruption and } \\
\text { transduction (PCR-product is } \\
\text { synthesized in case of IF3 gene } \\
\text { conservation only) }\end{array}$} & caggaagttcgcttaacagg \\
\hline 10 & & ggttagcgtgcttgtgc \\
\hline 11 & \multirow{2}{*}{$\begin{array}{c}\text { Screening of IF3 disruption and } \\
\text { transduction (PCR-products from IF3 } \\
\text { gene and from disruption cassette are } \\
\text { different in size) }\end{array}$} & gacgtaaatgaagtgatcgagaag \\
\hline 12 & & ggttagcgtgcttgtgc \\
\hline 13 & \multirow{2}{*}{ AIM23 cloning into pET32a } & gactCATATGaatgcatcatctaccacaga \\
\hline 14 & & ctagCTCGAGcatttcattcattttttttctct \\
\hline 15 & \multirow{2}{*}{$\mathrm{AIM} 23 \Delta \mathrm{N} \Delta \mathrm{C}$ cloning into $\mathrm{pET} 32 \mathrm{a}$} & gactCATATGtggagcaccgggacaga \\
\hline 16 & & ctagCTCGAGtggtttaacgtcctttggta \\
\hline 17 & \multirow{2}{*}{ IF3 cloning into $\mathrm{pET} 32 \mathrm{a}$} & atgcCATATGaaaggcggaaaacgagttc \\
\hline 18 & & actgCTCGAGctgtttcttcttaggagcg \\
\hline 19 & \multirow{2}{*}{$\begin{array}{l}\text { Screening of pET32a-based } \\
\text { constructs }\end{array}$} & gctagttattgctcagcgg \\
\hline 20 & & atgcgtccggcgtaga \\
\hline
\end{tabular}

4 